International Journal of Engineering \&Technology, $8(4)(2019) 535-542$
International Journal of Engineering \& Technology
SPC
Website: www.sciencepubco.com/index.php/IJET
Research paper

\title{
Scenario development for improving supply chain perfor- mance using the system dynamics approach
}

\author{
Imam Santoso ${ }^{1 *}$, Miftahus Sa'adah ${ }^{2}$, Siti Asmaul Mustaniroh ${ }^{3}$ \\ ${ }^{1}$ Department of Agroindustrial Technology, Faculty of Agricultural Technology, Universitas Brawijaya, Malang, 65145, Indonesia \\ *Corresponding author E-mail: imamsantoso@ub.ac.id
}

\begin{abstract}
Supply chain management integrates the entire business process of a product from upstream to downstream with the aim of delivering products to consumers in a timely manner and precise quantity without overriding profit. The application of dynamics systems is aimed to provide a holistic view of the system and to identify how interrelationship affects the system as a whole. System dynamics approach is used to analyze the efforts to improve performance. Besides being used as an analysis related to the model, system dynamics can also be used to formulate effective policy related to the profit distribution in case study of bell pepper supply chain. In this study, several scenarios were used as references to improve bell pepper supply chain performance in Regency X. The stake holders in the supply chain were farmer, middleman, and wholesaler. There were three sub-models used in system dynamics, namely the sub-model farmer, middleman, and wholesaler. The model in the system dynamics was then developed to find out the best scenario in improving the performance of bell pepper supply chain. The scenario developed consisted of 4 scenarios in which scenario 1 became the basic scenario as the comparison of simulation results. Then, Scenario 2 was a Supply-Demand arrangement to reduce losses obtained at the level of middleman and wholesaler. The policy of Scenario 3 was warehouse procurement, which was a model improvement scenario in Scenario 3. Lastly, Scenario 4 was an increase in the level of demand / market expansion without an increase in the number of production. The highest total supply chain profit from the four scenarios was in Scenario 3, while the lowest was Scenario 2.
\end{abstract}

Keywords: Bell Pepper; Policy; Profit; Simulation; Dynamics Model.

\section{Introduction}

Coordination or relation in a supply chain is very important; it is related to the importance of applying excellent supply chain management (Mentzer et al., 2001). Supply chain management integrates the entire business process of a product from upstream to downstream with the aim of delivering products to consumers in a timely manner and right number without overriding profit (Alexander, Walker and Naim, 2014). The main obstacle in supply chain management is the management of supply chain members with a high degree of complexity and uncertainty at each point of the supply chain members (Manuj and Sahin, 2011; Fu et al., 2016). Uncertainty and high complexity of supply chain are mostly found in agricultural products ( $\mathrm{Li}$, Zhang and Tang, 2015). Many variables in a supply chain that change dynamically over time can cause problems in the sustainability of a business (Wang et al., 2009). Thus, supply chain management has significant role in solving the problems (Chandrasekaran and Ranganathan, 2017).

Supply chain management plays an integral role in keeping the business cost low and the profitability as high as possible. There are many factors involved in supply chain management; one of the most important factors is flow (Umeda and Zhang, 2010). It includes product flow, information flow and financial flow (Xia and Chen, 2011). The challenge in implementing supply chain management is to maintain all three flows in an efficient way in order to maximize the income of the stakeholders in the supply chain. The flow consists of several dependent variables which mean that a variable will be affected by other variables. The thing that looks static, in a longer time horizon, will vary so that to describe the dynamic complexity between price, demand, supply, and time in a long time horizon, the system dynamics approach is chosen to build the desired model (Minegishi and Thiel, 2000 , Yen et al., 2016). In addition, several other advantages of system dynamics, among others, are more informative in presenting forecasting data, more accurate in describing short and medium term behavior, and deeper in developing a scenario (Sachan, Sahay and Sharma, 2005).

The application of dynamics systems aims to provide a holistic view of the system and to identify how interrelationship affects the system as a whole. The abilities to understand the whole system, analyze the interactions between various integrated system components, and supply feedback without dividing it into its components make system dynamics as an ideal method for modeling supply chain network (Briano et al., 2010). Previous studies have applied the dynamics system to the supply chain. In Asgari and Hoque (2013) study, system dynamics was proposed to understand dynamic behavior among the variables so that the top management could make effective decisions to improve long-term supply chain performance in the garment ready-made industry. Another study by Ge et al. (2004) employed system dynamics to determine the variables that can affect the decision to order materials. In this study, system dynamics is used as an analysis related to the model and a tool to formulate effective policy related to profit distribution in bell pepper supply chain in Regency X. 


\section{Materials and methods}

This research has used bell pepper in Regency $\mathrm{X}$ as a case study. This study involved primary and secondary data. The primary data were based on interviews with related parties in the supply chain network. The data taken were sales price, production cost, market demand, amount of crop and harvest time. Meanwhile, the secondary data consisted of distribution flow and inflation value.

1) To review the problem. This phase collected important information related to bell pepper supply chain system including the perspectives and assumptions of the parties involved (Alglawe, Schiffauerova and Kuzgunkaya, 2017). The information could be obtained from documents of government and non-government institutions including the results of research, interviews, or farmer group discussions. The experts chosen were seven people, some of them were chairmen of farmer groups, farmers, middlemen, wholesalers, agricultural services of Regency X, and agricultural instructors from Tutur Sub-district. This phase was intended to define the problem and find out various developing perspectives for the formation of existing models.

2) To build a conceptual model. Each element in the conceptual model was built to achieve the ideal goal. The model was built based on the results of activities identification in the systems which were the expressions of problem situations. This model is an adaptive process since it plays the feedback between the modeling process and the the expression of the problem (Pejic-Bach and Ceric, 2007). The conceptual model consisted of casual loop diagram and stock flow diagram.

3) To compare models with problem situations. This model was compared to the reality in order to find possible changes. All elements expressed perceptions and assessments of the activities modeled to find a decision. The decided model was then recommended for change (Mula et al., 2013). This model was performed by giving policy changes to the variables in the model.

4) To decide appropriate and desirable changes. This phase was intended to identify and find the desirable change systematically and precisely based on the situation. Changes could occur in the structure, procedure, or people's behavior.

\section{Result and discussion}

\subsection{Problem identification}

Bell pepper production in Regency X was not proportional to the opportunity and income earned. This was caused by weak bargaining position and market share of bell pepper farmer group compared to middleman and wholesaler. The farmer group still relied on middleman in marketing bell pepper. The amount of production costs sometimes only generated small profit for bell pepper farmers. Meanwhile, the middleman was able to generate greater profit with less risk because of strong capital market share and bargaining position. A common problem in agriculture in Indonesia is that farmer groups have not been able to market their products independently apart from the continuity of materials and their weak bargaining position (Prawiranegara et al., 2015). The bargaining position of supply chain stakeholders is affected by the support supply both from quality and quantity, the weaker the supply support provided, the weaker the bargaining position (Sachan, Sahay and Sharma, 2005).

The farmer group in Regency X sold the crop to a middleman who has become a regular customer and to restaurants and hotels relations. However, the crop sold to the restaurants and hotels was only in small amount with unfixed period of time. The concern of this marketing problem resulted in constraints on efforts to expand the land and increase the amount of production which has become a plan from the government to increase the potential of bell pepper in Regency X. The risk of low marketable value, damage to materials and low income resulted in farmers being reluctant to take such risks (Tolani and Hussain, 2013). Thus in this study a simulation was made to increase the amount of production and maximize profit from the supply chain that could benefit the farmers. The following is the bell pepper suply chain flow in Regency X.

\subsection{Conceptual model}

a) Causal loop diagram

Causal Loop Diagram is used to explore the relationship from the most significant variables in the system (Speller, Rabelo and Jones, 2007). The significance needed to be analyzed to explore the possible relationship and to illustrate the modeling of real condition onto the model. The causal loop diagram of bell pepper supply chain is shown in Figure 1.

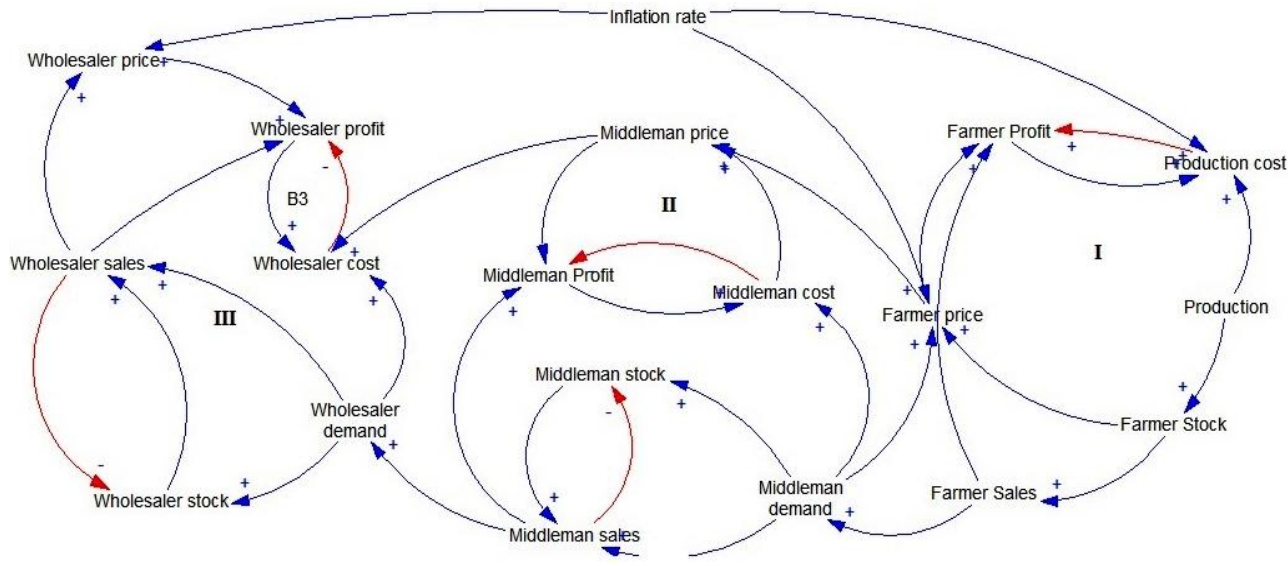

Fig. 1: Causal Loop Diagram of Bell Pepper Supply Chain.

Figure 1 is divided into 3 sub models (sub model I, II, and III) including farmers, middleman, and wholesaler models. The farmer submodel was formed from production cost, production, farmer stock, farmer price, farmer sales and farmer profit. This sub model consisted of two loops including R1 and B1. The first loop was R1, showing the relationships amongst production cost, production, farmer stock, farmer price, and farmer profit. The more bell peppers harvested, the more production cost, stock, and profit will be incurred. Increasing 
production capacity will be directly proportional to the increasing amount of production costs (Sebestyen and Juhasz, 2003). The second loop was B1, showing the relationship between farmer profit and production cost. The higher the profit value, the lower the production cost. Likewise, the higher the production cost, the lower the profit earned. Production cost will increase proportionally with operational cost, while net profit will decrease when the production cost is greater than income (Dahan and Srinivasan, 2011).

The middleman sub-model was formed from the middleman demand, cost, stock, price, sales and profit. This sub-model consisted of two loops, including R2, B2 and B4. The first loop was R2, showing the relationships amongst the middleman demand, cost, stock, price, and profit. The more bell peppers purchased, the greater the cost of purchasing, inventory and profit. The second loop was B2, showing the relationship between middleman cost and profit. Middleman cost consisted of transportation and ordering costs. Middleman will be more likely to gain greater income by increasing sale price to obtain higher profit. Otherwise, the profit gained will be relatively low (Oguoma, Nkwocha and Ibeawuchi, 2010). The third loop was B4, showing the relationship between the middleman sale and stock. The fewer sales made, while the order remains, the higher availability of the stock, and vice versa (Tamilia and Charlebois, 2009).

Wholesaler sub-model was formed from wholesaler demand, cost, stock, price, sales and profit. This sub-model consisted of two loops, namely R2, B3 and B5. The first loop was R2, showing the relationships amongst the wholesaler demand, cost, stock, price, and profit. The more bell peppers purchased, the greater the cost of purchasing, stock and profit. The second loop was B3, showing the relationship between the wholesaler cost and profit. Higher operational cost without an increase in the sale price will result in losses to traders (Tamilia and Charlebois, 2009). The third loop was B5, showing the relationship between wholesaler sales and stock. Higher availability of stock without effective sale will result in additional storage cost (Khan, Deng and Khan, 2016).

b) Stock Flow Diagram and Formulation

Figure 2 shows the stock flow diagram of the entire system consisting of sub-model I, sub-model II, and sub-model III, labeled respectively as farmer sub-model, middleman sub-model and wholesaler sub-model. The sub models indicated relationships between each other. DemandM was a variable in the middleman sub-model, having an effect on the supply demand ratio in the farmer sub-model. The MPrice variable or sale price at the middleman level was affected by the sale price of the product at the farmer level (FPPrice) and the effect of the supply demand ratio variable and the multiplier stock on the base price set at the middleman level. The ADMand variable in the middleman sub-model affected the ShortageW, SalesW, and CostW variables in the wholesaler sub-model.

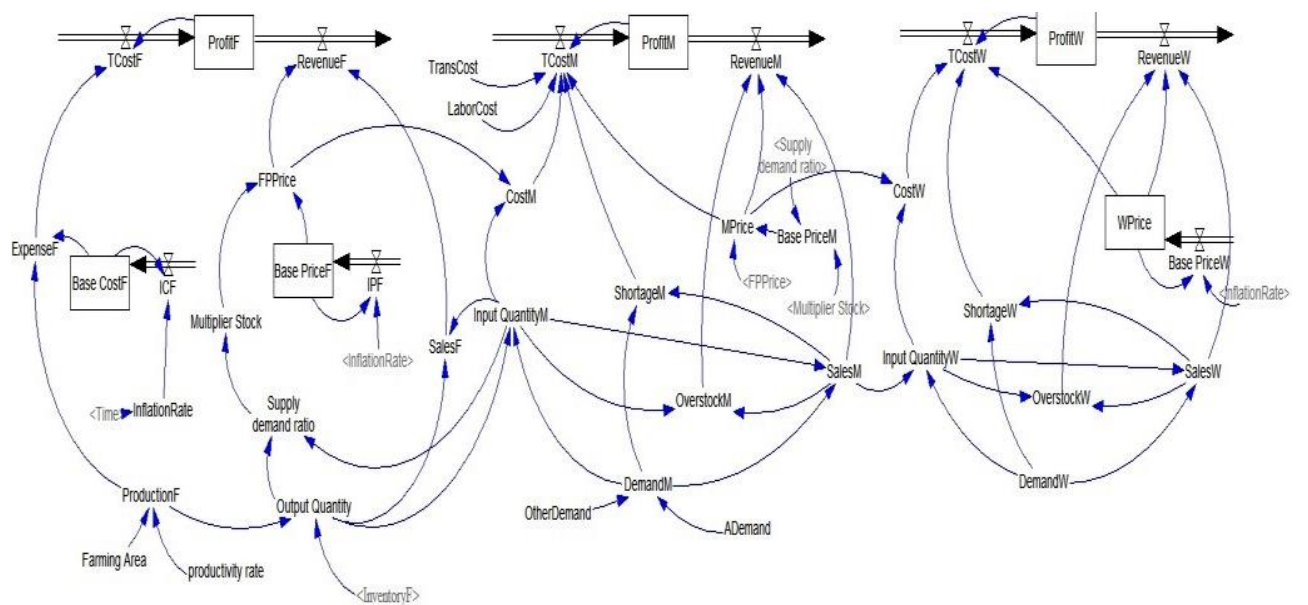

Fig. 2: Stock Flow Diagram of Entire Supply Chain.

\subsection{Scenario development}

The model developed was then verified and validated using an error syntax program. Vensim 6 was used to run the models. The basic model that has been verified and validated was then developed into a scenario. The scenarios were made by changing the parameters affecting the model. Scenarios can also be made by changing the structure of the model. This type of scenario requires sufficient knowledge about the system so that new structures proposed or experimented can improve system performance. The existing scenario was compared to the initial condition of the model, denoted as scenario 1 . Scenario 1 suggests that the existing stock flow diagram model will produce shortages and overstocks for the supply chain stakeholders. The amount of shortage and overstock will affect the amount of the profit gained by the stakeholders, thus a model change is decided to regulate the demand among stakeholders in the supply chain.

a) Scenario 2: Demand Arrangement

The result of Scenario 1 simulation shows that there is a rate of shortage and overstock in the middleman and wholesaler sub-models. In Scenario 2, a change in the model structure will be made by requesting arrangements to reduce the probability of shortages and overstocks in the supply chain activities. Demand arrangements can increase the profitability of the supply chain (Kirche, Kadipasaoglu and Khumawala, 2005). As for the middleman model and wholesaler model, input quantity variable is added. Input quantity is an intermediary variable to determine the ordering quantity in the previous chain. Input quantity will regulate the amount of ordering, which later will be adjusted to the rate of demand and supply. The following shows the result of the shortage and overstock changes at the middleman level and wholesaler level. 


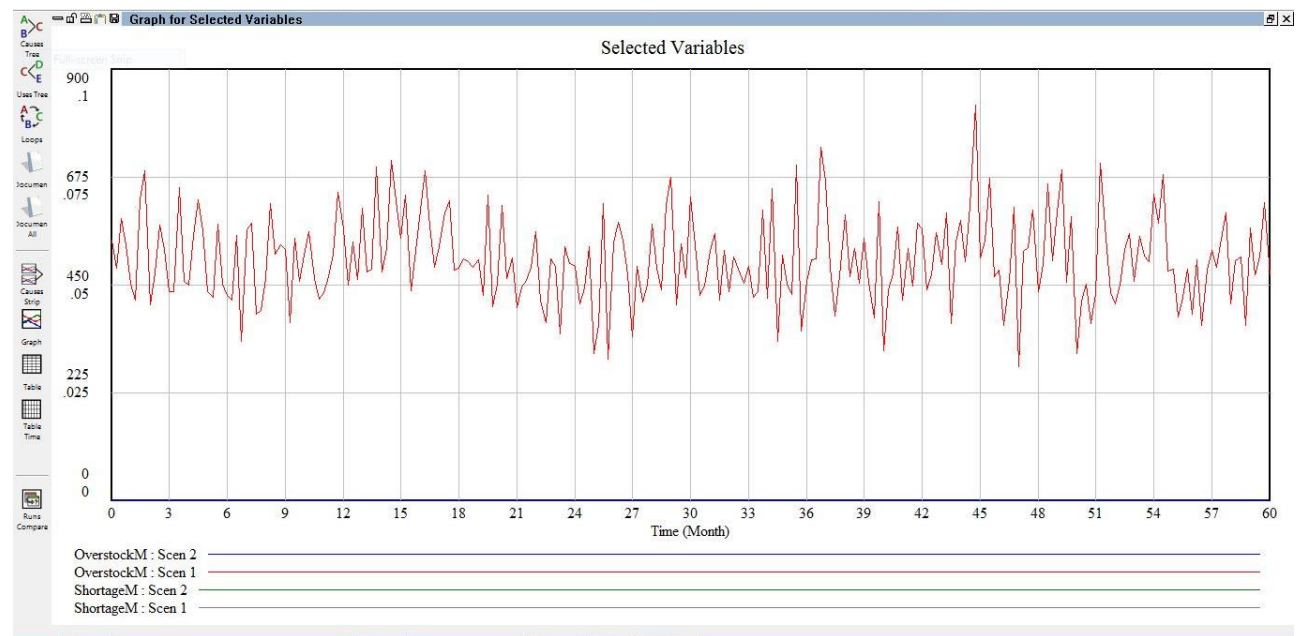

Fig. 3: Overstock and Shortage Simulation on Middleman Sub-model of Scenario 2.

Figure 3 shows the blue line and the green line indicating the rate of shortage and overstock in the middleman sub-model. The rate of the shortage and overstock incurred in scenario 2 is 0 . While Figure 4 shows the result of scenario 2 simulation for wholesaler shortage and overstock, which is 0 in value.

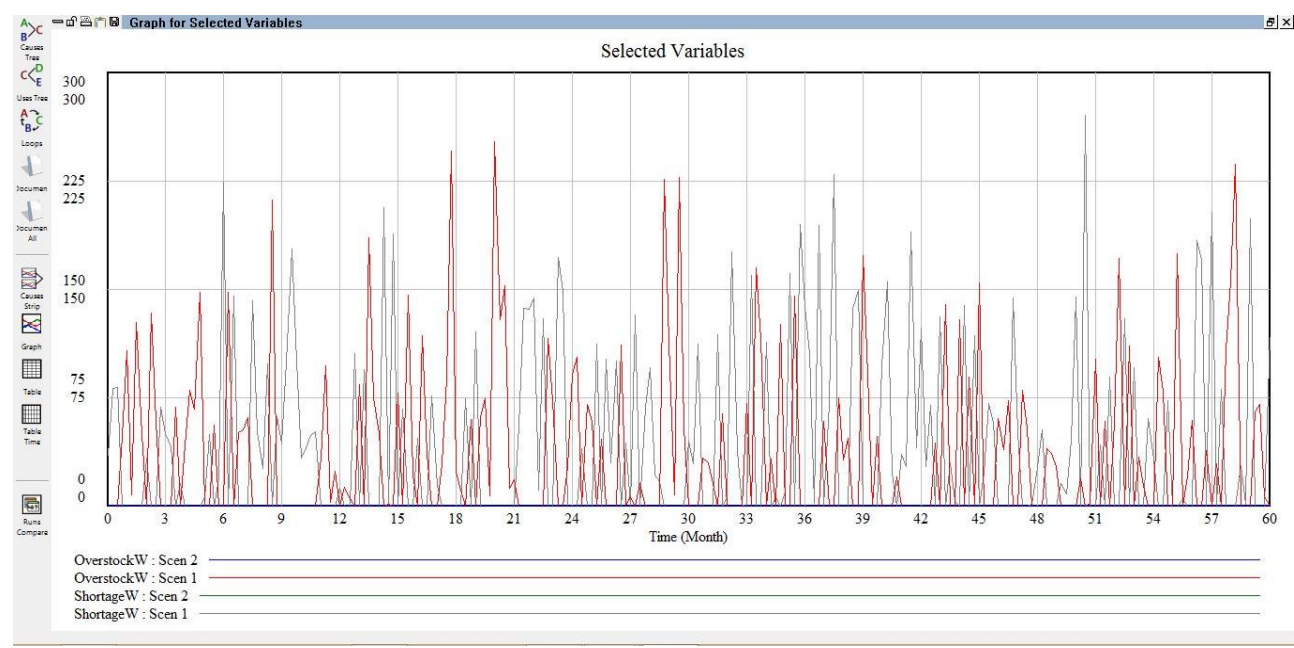

Fig. 4: Overstock and Shortage Simulation on Wholesaler Sub-Model of Scenario 2.

Basically, the profit increases when the rate of shortage and overstock decreases. However, this is different from the result shown in Figure 5. It shows the rate of profit from the result of scenario 3 simulation, indicating blue, green, and purple lines for successive profit of farmer, middleman, and wholesaler. The value of wholesalers increases, but that of farmer and middleman decreases. This happens due to the arrangement of supply and demand from farmers to middlemen. There is a supply limitation in the farmer sub-model because the middleman sub-model only orders according to the demand, whereas in scenario 1 the farmer sub-model sells all stocks to the middleman. Likewise, the middleman sub-model in scenario 1 will sell what they have purchased from the farmer sub-model. Therefore, when the supply amount decreases, the amount of profit obtained also decreases. There is no significant change in the wholesaler sub-model because the supply from the middleman sub-model is constant. The increase in profit is due to a reduction in shortage cost and overstock in scenario 1. Figure 6 shows that there are additional variables originating from the changes in scenario 2 in the form of overstock variables in the farmer sub-model. This overstock variable then turns into a cost added to TcostF, or the total cost at the farmer level. This overstock then reduces the rate of income in the farmer sub-model. 


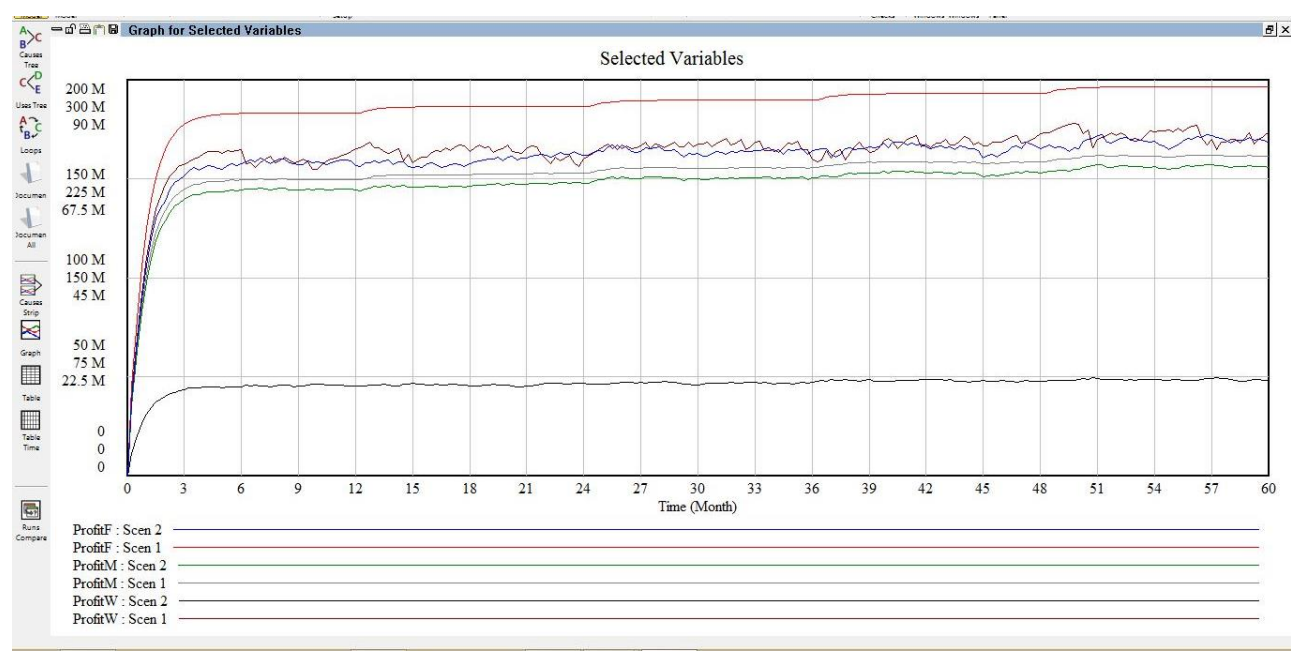

Fig. 5: Farmer, Middleman and Wholesaler Profit Simulation on Scenario 2.

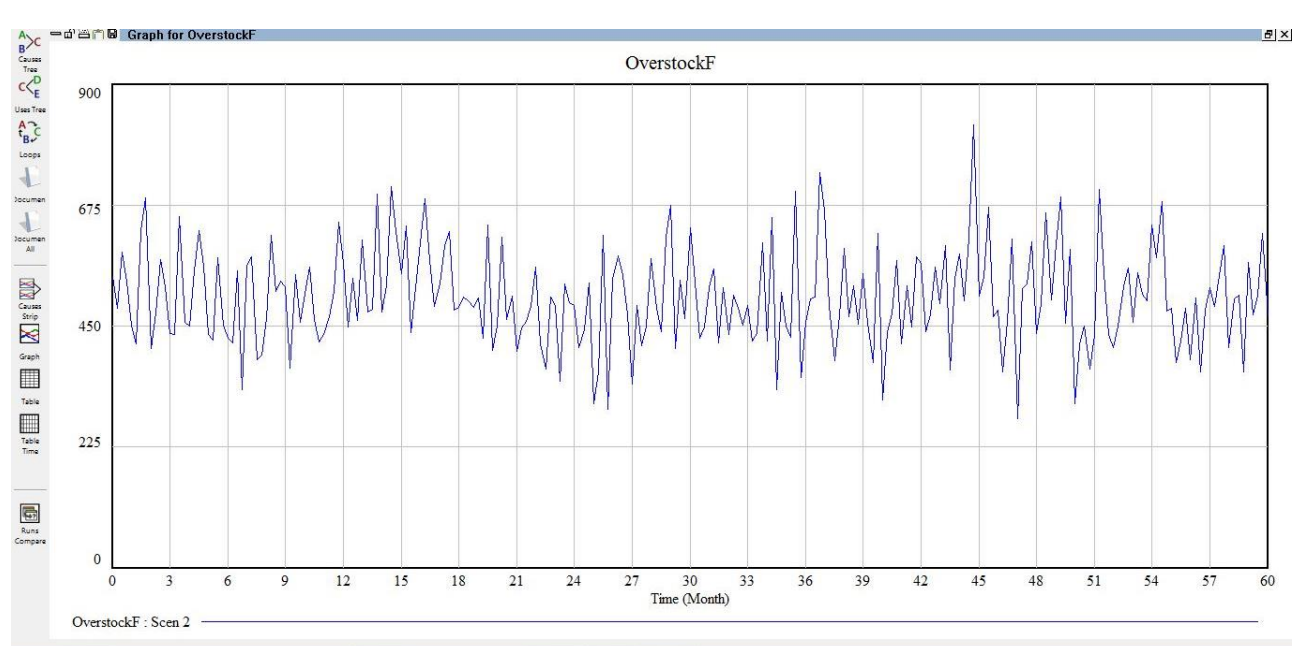

Fig. 6: Overstock on Farmer Sub-Model of Scenario 2.

b) Scenario 3: Additional Warehouse Facility

The farmers, as explained previously, experienced the lack of distribution facilities and infrastructure as one of the obstacles in improving supply chain performance. They were not sure when they should increase the rate of production since the unavailability of warehouses continues, and the market demand remained. In Scenario 2, the farmer sub-model has an additional overstock variable. Overstock can be referred as inventory.

In scenario 3, the inventoryF sub model will be added, which translates into the inventory at the farmer level. The addition of the inventoryF sub model will affect the output quantity in the farmer sub-model. In scenario 3, parameter changes in the form of an increase in the productivity rate (from 0.05 to 0.3 ), and an Ademand of $6500 \mathrm{~kg}$ per month for the middleman sub-model, will be made. The InventoryF variable is affected by the production and sales variables, where both variables are affected by the rate of production (ProductionF) and the rate of sales (SalesF) in the sub-model farmer.

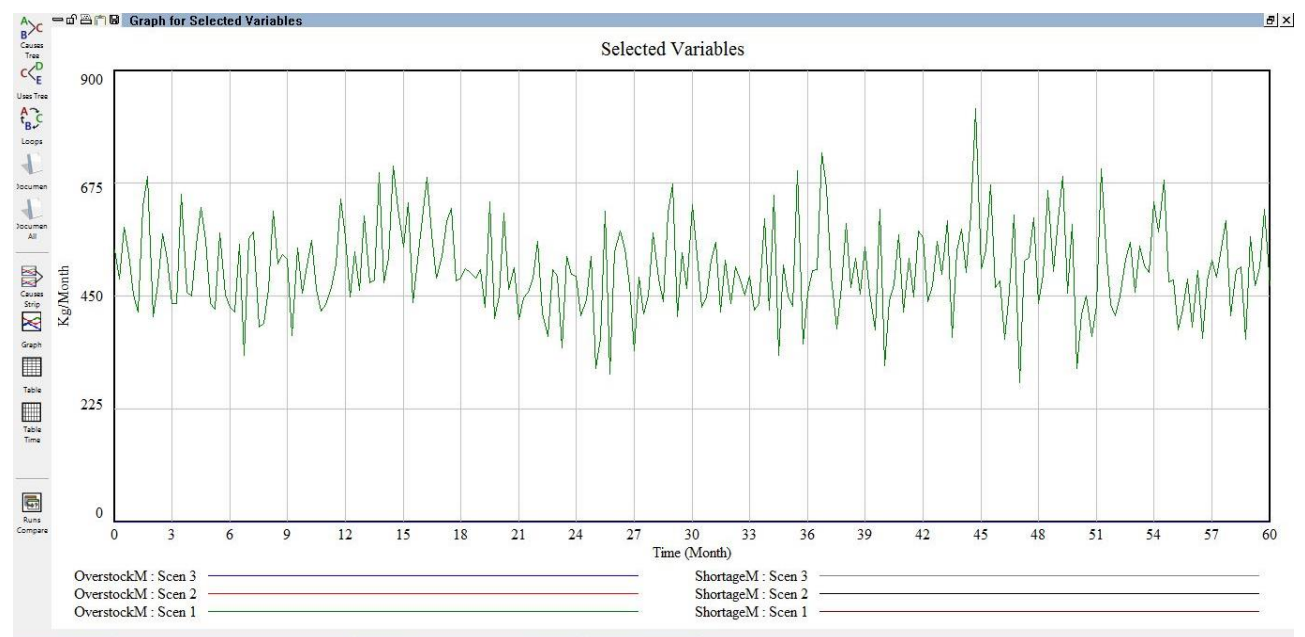

Fig. 7: Farmer, Middleman and Wholesaler Profit Simulation on Scenario 3. 


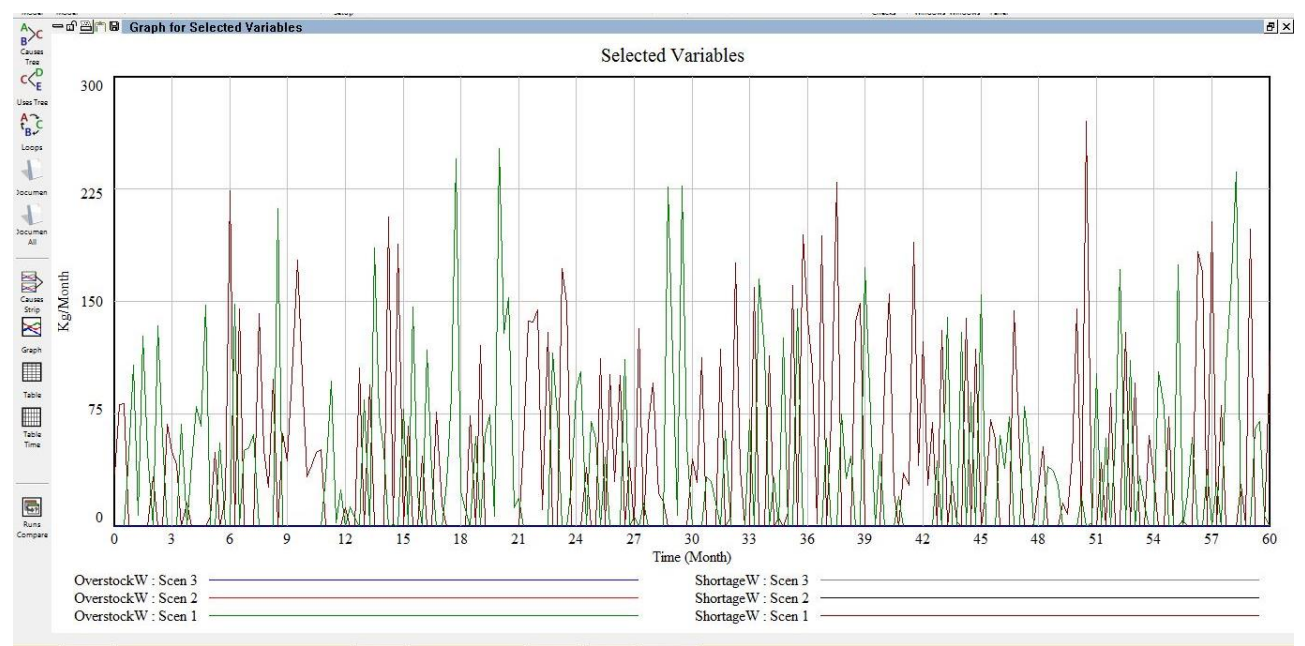

Fig. 8: Overstock on Farmer Sub-Model of Scenario 3.

Based on the policy changes in Scenario 3, the result of the profit simulation is shown in Figure 7, where the profit rate from the simulation result in Scenario 3 is illustrated in dark blue, gray, and light blue lines, respectively labeled as farmer profit, middleman profit, and wholesaler profit. The rate of farmer and middleman profits increase, while that of the wholesaler remains, as suggested by scenario 2 . This happens due to the absence of change in the demand rate in the wholesaler sub-model. Figure 8 shows the application of scenario 3 , indicating no shortage and overstock.

c) Scenario 4: Changes in Demand Rate

In scenario 4, a change in the demand rate is made for the wholesaler sub model, which is $7000 \mathrm{~kg}$ per month. Based on the change of policy in scenario 4, the result of the profit simulation is shown in Figure 9, illustrating the profit rate from the simulation result in scenario 3 in dark blue, dark green, and dark purple lines, labeled respectively as farmer profit, middleman profit, and wholesaler profit. The rate of farmer and middleman profits decrease, while that of the wholesaler increases. This happens due to the absence of additional production from farmers, thus the lowest rate of supply, while the wholesaler sub model shows maximum rate of supply. This causes an increase in profit in the wholesaler sub-model.

As previously explained, the profits of the farmer and middleman sub models decreased. Therefore, it is necessary to explain that the overall increase in profit can be made as long as supply and demand increase. A balanced rate of demand and supply will affect the rate of fulfillment and continuity of supply. Increasing demand without coordination with other stakeholders will only cause losses (Parvez et al., 2018).

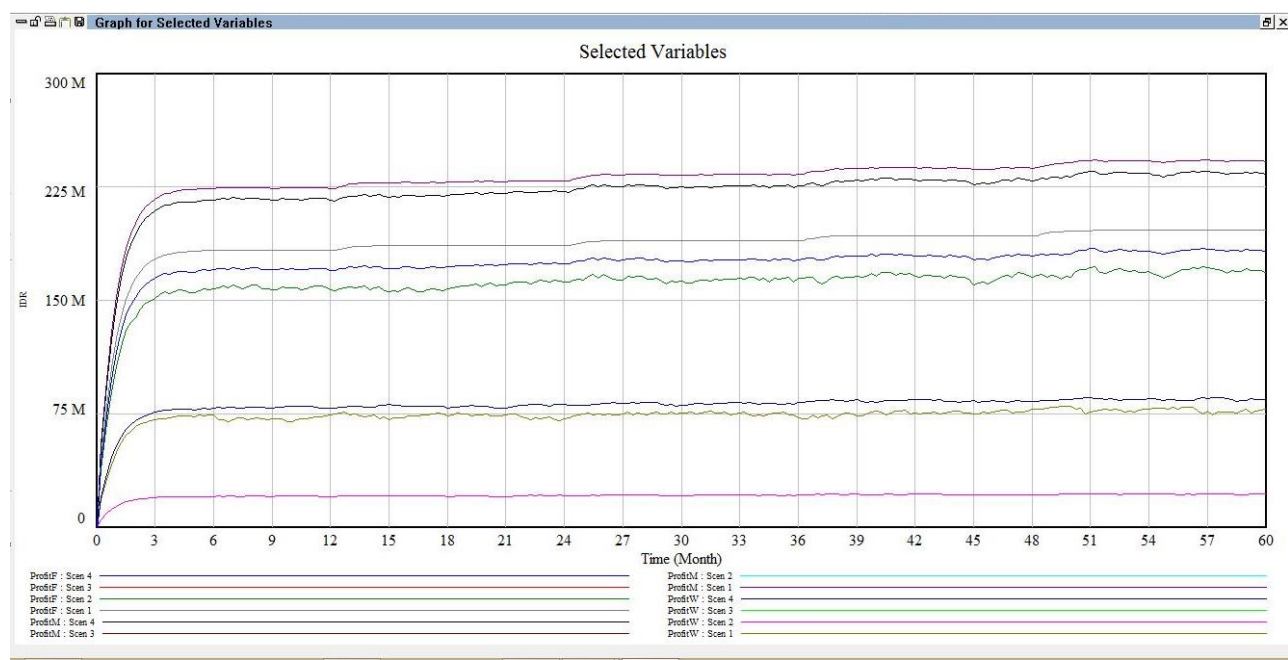

Fig. 9: Farmer, Middleman and Wholesaler Profit Simulation on Scenario 4.

\subsection{Scenario analysis}

Analysis of the result of the scenarios in Table 1 shows the final income value for each stakeholder in the supply chain, and the total cost in each scenario. Scenario 1 plays as the basic scenario for all policy scenarios due to the absence of policy changes. Total Supply Chain Profit shows the performance of the chain in the supply chain system.

Table 1: Profit Comparison of Each Scenario

\begin{tabular}{lllll}
\hline Condition & Supply Chain Stakeholders & & Wholesaler & Total SC Profit \\
& Farmer & Middleman & Rp72,731,600 & Rp472,305,600 \\
\hline Scenario 1 & Rp180,000,000 & Rp219,574,000 & Rp75,523,500 & Rp439,825,500 \\
Scenario 2 & Rp152,868,000 & Rp211,434,000 & Rp75,523,500 & Rp514,391,500 \\
Scenario 3 & Rp189,934,000 & Rp248,934,000 & Rp78,040,900 & Rp455,908,900 \\
Scenario 4 & Rp166,434,000 & Rp211,434,000 & & \\
\hline
\end{tabular}


Table 1 shows that the value in red indicates the lowest profit in the supply chain of the scenario, while the one in blue indicates the highest profit. The lowest profit value for farmers is in Scenario 2 and the highest one is in Scenario 3. The lowest profit value for middlemen is in Scenario 2 and the highest one is in Scenario 3. The lowest profit value for wholesalers is in Scenario 1 and the highest one is in Scenario 4. The highest total supply chain profit is in Scenario 3 while the lowest is in Scenario 2. An increased supply balanced with a good demand supply system and good cooperation between supply chain stakeholders will increase the profit in the system (Wahdan and Emam, 2017). The following is an illustration of SFD changes in the overall bell peppers supply chain based on the best scenario with the highest supply chain profit in Scenario 3 (Figure 10).

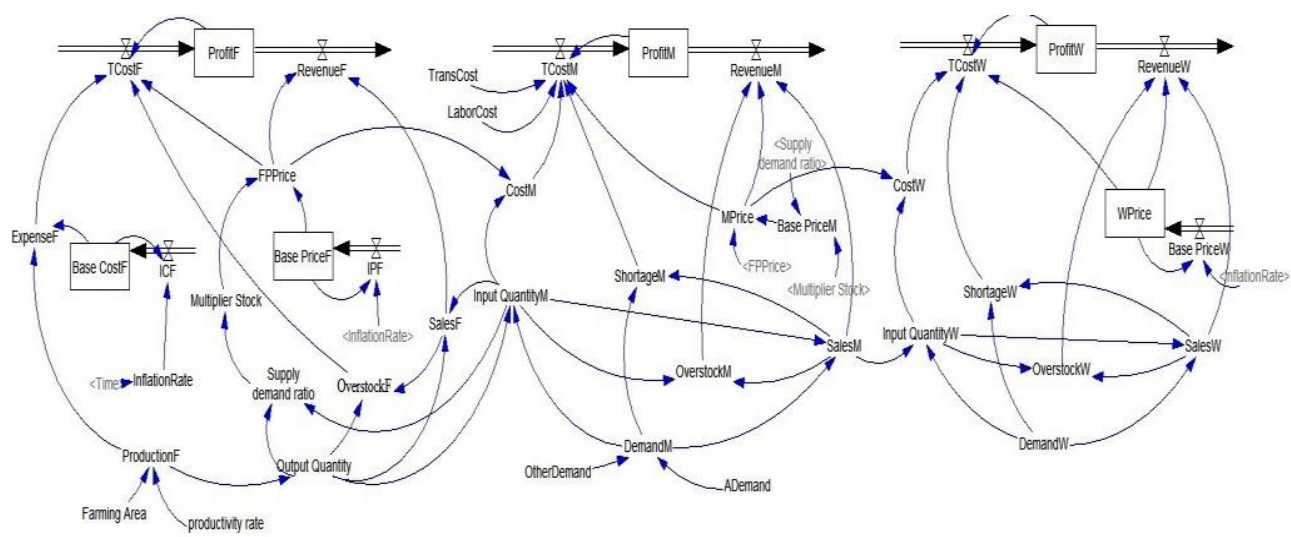

Fig. 10: Stock Flow Diagram Changes of Bell Pepper Supply Chain in Scenario 3.

\section{Conclusion}

In increasing the performance of the bell peppers supply chain using system dynamics, there were three sub models used, including the farmer, middleman, and wholesaler sub-models. The developed model was adjusted to the real conditions by conducting verification and validation. Validated and verified models will then arranged into several policy scenarios to find out the variables affecting the improvement of the bell peppers supply chain performance in Regency X with the profit approach to the supply chain cost. The scenario that has been simulated consisted of 4 scenarios where Scenario 1 played as the basic scenario for comparison of simulation results. Scenario 2 was about a Supply-Demand arrangement to reduce losses obtained at middlemen and wholesaler levels in scenario 1. Policy Scenario 3 was about storage and warehouse, which was the improvement of the model in scenario 3. Scenario 4 was about the increasing demand/market expansion without increased production. The highest total supply chain profit of the four scenarios was in Scenario 3, with Scenario 2 suggesting the lowest value.

\section{Acknowledgement}

The authors gratefully acknowledge Faculty of Agricultural Technology, Universitas Brawijaya, Malang, Indonesia and other parties for supporting facilities and opportunities to carry out this research.

\section{References}

[1] Ministry of Industry. Overview of Cocoa Industry. Jakarta: Secretariat General of the Ministry of Industry, 2007 (Text in Indonesia.

[2] Directorat General of Plantation. Plantation Statistics Indonesia Cocoa Commodity 2013-2015. Jakarta: Directorat General of Plantation, 2014 (Text in Indonesia).

[3] T. Wahyudi, T. R. Panggabean, and Pujiyanto. Cocoa Complete Guide. Jakarta: Penebar Swadaya, 2008 (Text in Indonesia).

[4] P. Singhal, G. Agarwal, and M.L. Mittal, "Supply Chain Risk Management: Review, Classification and Future Research Directions" International Journal of Business Science and Applied Management, vol. 6, pp. 15-42, 2011. https://doi.org/10.4018/978-1-60960-135-5.ch002.

[5] K. O. Sarpong, O.F. Alexander, and E.K. Anin, "An Assesssment of Supply Chain Risk in the Cocoa Industry in the Ashanti Region, Ghana" International Journal of Humanities and Social Science, vol. 3, pp. 191-201, 2013.

[6] H. Aini, M. Syamsun, and A. Setiawan, "Risk of Cocoa Supply Chain in Indonesia with Analytic Network Process and Failure Mode Effect Analysis Integrated Method" Journal of Management \& Agribusiness., vol. 11, pp. 209-219, 2014 (Text in Indonesia).

[7] Y. R. Perdana, "Logistics Information System for Supply Chain of Agricultural Commodity" Social and Behavioral Sciences. vol. 65, pp. 608-613, 2012. https://doi.org/10.1016/j.sbspro.2012.11.172.

[8] W. Ho, T. Zheng, H. Yildiz, and S. Talluri, "Supply Chain Risk Management: A Literature Review" International Journal of Production Research, vol. 53, pp. 5031-5069, 2015. https://doi.org/10.1080/00207543.2015.1030467.

[9] I. Etikan, S. A. Musa, and R. S. Alkassim, "Comparison of Convenience Sampling and Purposive Sampling" American Journal of Theoretical and Applied Statistics., vol. 5, pp. 1-4, 2016.

[10] I. N. Pujawan and L. H. Geraldin, "House of Risk: A Model for Proactive Supply Chain Risk Management" Business Process Management, vol. 15, pp. 963-967, 2009. https://doi.org/10.1108/14637150911003801.

[11] J. A. P. Mendoza, "Analytical Hierarchy Process and SCOR Model to Support Supply Chain Re-design” International Journal of Information Management, vol. 34, pp. 634-638, 2014. https://doi.org/10.1016/j.ijinfomgt.2014.06.002.

[12] A. Lutfi and H. Irawan. 2012. Analysis of Supply Chain Risk Using House of Risk Model (Case Study at PT. XXX). Journal of Indonesia Management, vol. 12, pp 1-11, 2012 (Text in Indonesia).

[13] I. Alwi, "Empirical Criteria in Determining Sample Size on Testing Statistical Hypothesis and Grain Analysis" Formatif Journal., vol. 2, pp. 140148, 2015 (Text in Indonesia).

[14] Rahmatin, N., Santoso, I., Indriani, C., Rahayu, S., Widyaningtyas, S., Integration of the Fuzzy Failure Mode and Effect Analysis (Fuzzy FMEA) and the Analytical Network Process (ANP) in Marketing Risk Analysis and Mitigation. International Journal of Technology. vol.9(4), pp.809-81, 2018. https://doi.org/10.14716/ijtech.v9i4.2197.

[15] Santoso, I., Sa'adah,M., Wijana, S.,. QFD and Fuzzy AHP for Formulating Product Concept of Probiotic Beverages for Diabetic. Telkomnika, 15(1), pp. 391-398, 2017. https://doi.org/10.12928/telkomnika.v15i1.3555. 
[16] E. N. Hayati, "Supply Chain Management (SCM) dan Logistic Management" Journal of engineering dynamics., vol 8, pp. 25-34, 2014 (Text in Indonesia).

[17] B. Utoyo. Geography Opens the World's Horizon. Bandung: Setia Purna Inves, 2009 (Text in Indonesia).

[18] P. Mensah and Y. Merkurvey, "Developing a Resilient Supply Chain" Social and Behavioral Sciences., vol. 110, pp. 309-319, 2014. https://doi.org/10.1016/j.sbspro.2013.12.875

[19] S. I. Tjipto, "Performance Analysis on Supply Chain Management of Construction Services Company" Journal of Management, pp. 1-12, 2014 (Text in Indonesia).

[20] N. E. Wahyudin and I. Santoso, "Modelling of Risk Management for Product Development of Yogurt Drink Using House of Risk (HOR) Method" The Asian Journal of Technology Management, vol. 2, pp. 98-108, 2016. https://doi.org/10.12695/ajtm.2016.9.2.4.

[21] L. Laricha, Rosehan, and Cynthia, "Proposed Quality Improvement with Six Sigma and FMEA Method (Mode of Failure and Effect Analysis) On MBC Roller Conveyor Production Process at PT. XYZ" Scientific Journal of industrial engineering., vol. 1, pp. 88-94, 2013 (Text in Indonesia)

[22] T. Kusmantini, A. D. Guritno, and H. C. Rustamaji, "Mapping of Supply Chain Risk in Industrial Furniture Base on House of Risk Framework" European Journal of Business and Management., vol. 7, pp. 104-115, 2015.

[23] F. Tampubolon, A. Bahaudin, and P. F. Ferdinant, "Management of Supply Chain Risk Using House of Risk Method" Industrial Engineering Journal., vol. 1, pp. 222-226, 2013 (Text in Indonesia).

[24] S. J. Benjamin, M. S. Marathamuthu, and U. Murugalah, “The Use of 5-WHYs Technique to Eliminate OEE's Speed Loss in A Manufacturing Firm" Journal of Quality in Maintenance Engineering., vol. 21, pp. 29-39, 2015. https://doi.org/10.1108/JQME-09-2013-0062.

[25] D. I. Handayani “A Review: Potensi Risiko Pada Supply Chain Risk Management”. Jounal of Industrial Spectrum, vol. 14, pp. 1-108, 2016 (Text in Indonesia). https://doi.org/10.12928/si.v14i1.3701.

[26] R. Firdausa, N. W. Setyanto, and R. Yuniarti, "Risk Analysis of Risk Analysis Project Tool Queue C2000 Using House of Risk (Case Study at PT Cendana Teknika Utama)" Journal of Engineering and Industrial System Management, vol. 3, pp. 431-442, 2015 (Text in Indonesia).

[27] B. R. Kristanto and N. L. P. Hariastuti, "Application of House of Risk (HOR) Model for Risk Mitigation on Leather Raw Materials Supply Chain" Scientific Journal of Industrial Engineering., vol. 13, pp. 149-157, 2014 (Text in Indonesia). 